\title{
FURTHER IMPROVEMENT OF PHYSICAL TRAINING AND SPORTS MANAGEMENT
}

\author{
Farhod Karimovich Turdiev
}

Candidate Of Pedagogical Sciences, Associate Professor, Department of "Sports Management", Institute Of Retraining And Advanced Training Of Physical Culture And Sports, Uzbekistan

Ziyodulla Shukhratillaevich Khadiyatullaev

Teacher, Department of "Sports Management", Institute Of Retraining And Advanced Training Of Physical Culture And Sports, Uzbekistan

\section{ABSTRACT}

The article highlights the work done in the field of physical culture and sports during the years of independence of the Republic of Uzbekistan, reveals the problems, mistakes and shortcomings in the management of sports.

On the basis of author's scientific researches, it provides data about the social significance of moral factors in ensuring the priority of management in the field of sport.

KEYWORDS:- Physical education and sport managing of physical education and branches of sport, scientific approaches on sport, spiritual factors, special tests on "Alpomish" and "Barchinoy", sport facilities, higher results of sport.

\section{INTRODUCTION}

From the first days of Uzbekistan's independence, the continuation of social, economic, political and spiritual reforms has introduced new methods of governing the state and organizing all activities. The form, content and main objectives of these methods are reflected in the adopted laws, decisions and speeches of the President of Uzbekistan and statements at various meetings. These processes also apply to the activities of physical education and sports.

Today requires the abandonment of the existing command-and-control method of management or their use in accordance with the conditions and requirements of the new era. Some of the work methods mentioned above are being replaced by new methods such as initiative, creativity and dedication. They are widely used in public sports events, folk games, sports teams, improving their sports skills, attracting children and women to sports, material and financial support of sports and give positive results. In order for Uzbek athletes to regularly participate in the Olympic and Asian Games, world and continental championships and other prestigious sports competitions and win prizes, sports organizations need to rely on international standards and experience in organizing trainings for national teams. This, in turn, requires a new approach to work in management, the use of the necessary material and technical resources and the search for ways of self-financing, as well as more and better research.

In this article, we want to highlight some of the problems, mistakes and shortcomings that we 
CURRENT RESEARCH JOURNAL OF PEDAGOGICS 2(10): 91-95,

October 2021 DOI: https://doi.org/10.37547/pedagogics-crjp-02-10-17

ISSN 2767-3278

(C)2021 Master Journals

Crossref do) 81 Google

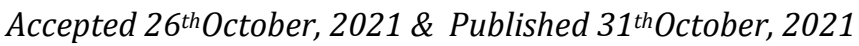

face in the management of physical education and sports today.

In the process of transition to free market relations, the main task of economic management methods is to create and effectively use new methods of economic mechanisms, as well as an environment of interest, which will reduce the cost per unit of product (service) produced.

In Buusul, people are made to work effectively by revealing their personal and group interests. For this purpose, it is important to pay extra wages, give bonuses, and reward one with a large sum of money.

Economic methods take the lead among all methods of management. A leader at any level should be familiar with the content of these methods and be able to apply them correctly.

In the early days of independence, mistakes and shortcomings in this method led to the departure of athletes and coaches, who ranked high in several world rankings, to different countries (Russia, Kazakhstan, China, India, Malaysia, Indonesia, Singapore, Thailand). , Arab and other countries). This is still the case today. On the one hand, it is possible to understand them, because everyone needs material support, but where did the feelings of hard work, conscience and pride for the Motherland, patriotism, national pride, honor go? 


\section{The social significance of spiritual factors in ensuring the priority of sports management}

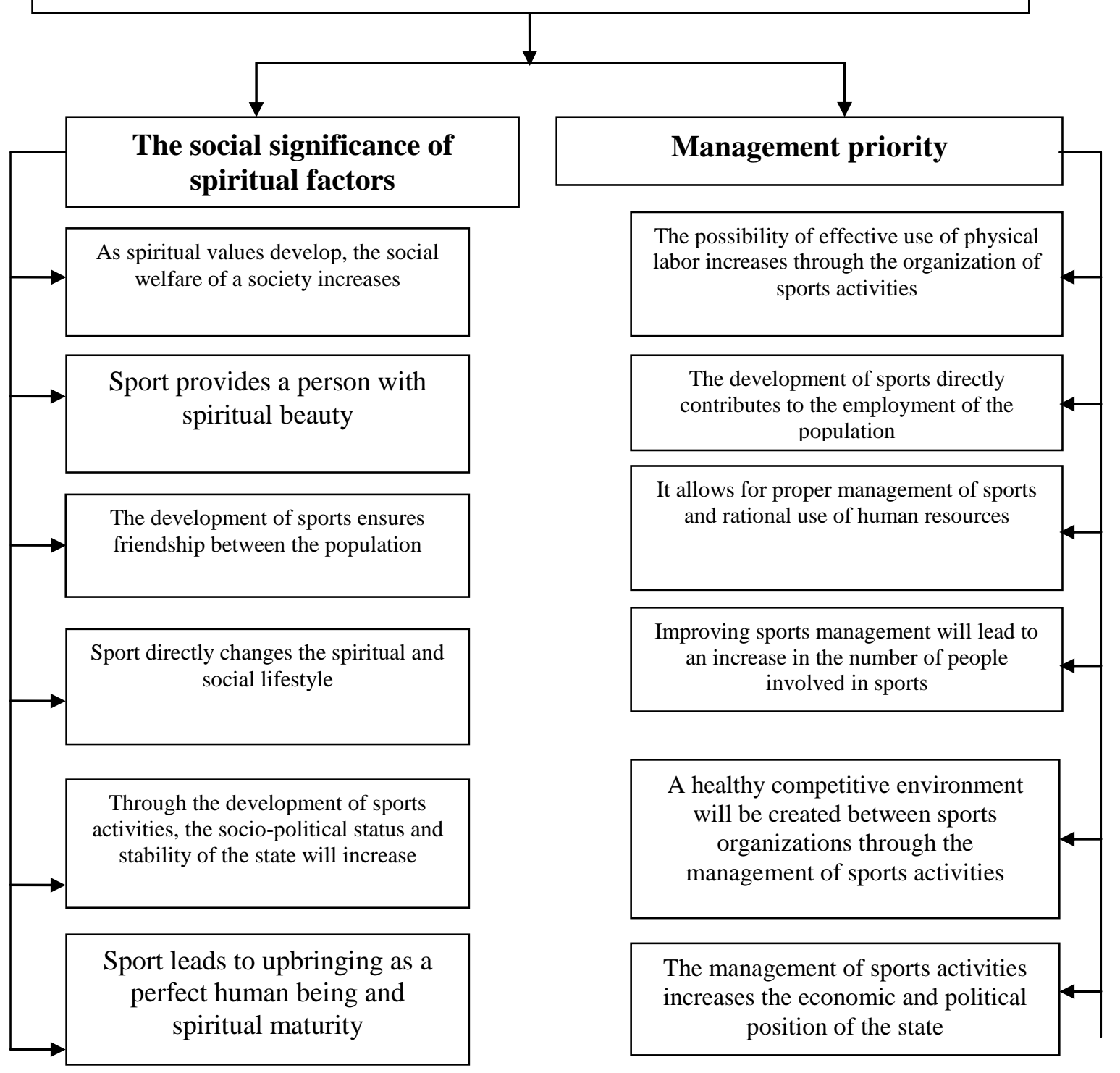

Figure 2.1. The social significance of spiritual factors in ensuring the priority of sports management

In order to comprehensively develop children's sports, the number of children and adolescents involved in sports at the national and regional levels has been determined, and priority and promising sports are being developed, taking into account the scientific and medical bases and 
CURRENT RESEARCH JOURNAL OF PEDAGOGICS 2(10): 91-95,

October 2021 DOI: https://doi.org/10.37547/pedagogics-crjp-02-10-17

ISSN 2767-3278

(C)2021 Master Journals

\section{Crossref doi) gr Google}

Accepted $26^{\text {th }}$ October, 2021 \& Published $31^{\text {th }}$ October, 2021

natural conditions of the regions.

However, in the early years, gross errors were made in the formulation of the monitoring of the increase in the number of regular participants in sports and in the collection of statistics. For example, one athlete in athletics from both a high school and a sports school, if he or she is studying at the College of Olympic Reserve, has been reported in statistics. As a result, one athlete has more than three.

In many reports on physical education and sports, chase, addition, and report-only activities are still common today. In particular, we can observe in the statistics on the number of sports facilities, the number of students who passed the complex test standards "Alpomish" and "Barchinoy", the number of sporting events.

At present, the competition between the states, the competition for the demonstration of strength, is gaining priority in two areas physical culture and sports, as well as in the field of intellectual activity. In scientific terms, the realization of the physical and intellectual potential of the people, the formation of appropriate resources in this regard is becoming a guarantee of development and prosperity in the XXI century.

The importance of a scientific approach to the management of physical culture and sports and the achievement of high sports results is very high. In today's world of sports there is a constant sharp increase in results, updating records, changing competition rules, improving sports medicine (medical equipment, diagnostics, pharmacology, treatment, etc.), providing modern sports equipment, planning and organizing sports training, effective management techniques. Application requires a scientific approach. In developed countries, there are scientific laboratories for each sport, equipped with modern equipment. The system of training highly qualified athletes involves a group of researchers, sports psychologists, medical staff, managers and others. In our country, in order to train highly qualified athletes, the coaches in charge of the head and senior coaches of the sports are working blindly.

Every educated person, especially management staff, should have the necessary knowledge of the basics of the scientific organization of labor, the development of work for this purpose and personal leadership. The scientific organization of management means the application of theoretical knowledge and practical work experience, as well as the results of the most advanced and science-based work, their implementation, the achievement of relevant results. This is often manifested in the management of large teams in sports, leading them to success, achieving high results. However, the work being done in the field of scientific approach in sports today is not satisfactory. The main reasons for this are:

- Lack of knowledge of young people graduating from master's departments in higher education institutions;

- $\quad$ Lack of potential scientific staff;

- Low practical significance of the research work carried out;

- Non-implementation of scientific innovations;

- Head coaches or responsible managers for sports

- Irresponsible approach to research;

- $\quad$ Lack of equipment required for research work or does not meet modern requirements, etc.

Of course, given the role and responsibility of educating the younger generation in a physically 
CURRENT RESEARCH JOURNAL OF PEDAGOGICS 2(10): 91-95,

October 2021 DOI: https://doi.org/10.37547/pedagogics-crjp-02-10-17

ISSN 2767-3278

(C)2021 Master Journals

\section{Crossref do: 81 Google}

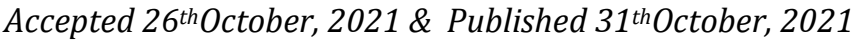

healthy, mentally mature and harmoniously developed, the leaders and staff responsible for the development of physical culture and sports in local governments should pay more attention to:

- Assistance in the formation of public associations of physical culture and sports and the expansion of sports;

- The organization of work on passing special tests "Alpomish" and "Barchinoy" among the population, especially schoolchildren;

- Assistance in providing sports facilities with coaches and modern sports equipment;

- control over the organization of sports and health activities in and out of school in connection with the system of three-stage continuous competitions introduced in the country;

- Development of sports suitable for children living in villages, remote villages, mountain or desert areas and involving them in mass sports competitions;

- a special approach to the restoration and organization of children's playgrounds on the ground and increase the responsibility of officials in this regard, etc.

It is also necessary to hold regular district, city and regional championships of local competitions, identify winners and provide appropriate incentives by organizing events at a high level to improve the results of sports in the regions (especially Olympic sports). It is necessary to attract strong athletes and coaches, as well as funds for the formation of national teams, and increase the responsibility of local authorities in this regard.

\section{REFERENCES}

1. Karimov IA High spirituality is an invincible force.-T .: Spirituality, 2008.-173 $\mathrm{p}$

2. Abdumalikov R. Theoretical bases of physical culture and sports management.T .: UzSWLI, 1996. -123 p.

3. Aleshin V.V., Kuzmichova E.V., Pereverzin I.I. Management of foreign stadiums and sports and recreation centers. -M., 1997.251s.

4. Ethics. Text of lectures. -T., 2000.- 151 p.

5. Valijonov R., Kobulov O. Fundamentals of Management. -T., 1999.-114 p.

6. Danilov-Danilyan V.I. Modern management: principles and rules. -M., 1992.-69 p.

7. Handbook of a sports manager. Reference manual. - M., 1997. - 328 p.

8. Nurmukhamedov K. Socio-economic problems of physical culture and sports. T., UzSWLI, 1991. -89 b. 